\title{
Exploring complex issues: Insights from classrooms, courses and conversations
}

\author{
Anne D. Cockburn
}

Published online: 25 September 2011

(c) Springer Science+Business Media B.V. 2011

As researchers we are continually developing our knowledge and understanding of mathematics education and, indeed, of the subject itself. In this issue we explore some of the current concerns we face as a community of mathematics educators. The challenges are undoubtedly complex. Here I would like to share some insights from classrooms, courses and conversations.

Over the years mathematics curriculum materials have drawn considerable attention and raised some interesting issues particularly in the way teachers have adapted them for classroom use. Unlike many studies Jeffrey Choppin's work benefits from being longitudinal. In Learned adaptations: Teachers' understanding and use of curriculum resources, he discusses three teachers' (grades 6-8) evolving implementation of curriculum materials having observed their use on at least three occasions. While there were some similarities in their practice he explores marked differences in how they revised their tasks and how these adaptations related to student sense making. Significantly he provides an example how one of the teachers adopted curriculum resources in ways that built on and developed the designers' original intentions.

Managing whole group discussions is notoriously difficult and little understood. In their article-Extending students' mathematical thinking during whole group discussionsNesrin Cengiz, Kate Kline and Theresa Grant closely examine eight episodes taken from six elementary classrooms. They explain that the teachers, having recognised opportunities to build new connections or address misconceptions, engaged in 'a skilful dance' in order to extend student thinking. While the authors acknowledge the need for further work on the topic they succeed in providing considerable insight into, '...much needed detail on what extending students' mathematical thinking looks like and which instructional actions are instrumental in achieving the potential for extending episodes.'

Teachers' resources - particularly in terms of time and energy — are often limited, and therefore, it is important that the professional development they are offered is of the highest quality. In their article Kelli Nipper and her colleagues explore the relationship between teachers' expectations and actual experiences of a 1-week professional

A. D. Cockburn $(\bowtie)$

School of Education and Lifelong Learning, University of East Anglia, Norwich NR4 7TJ, UK

e-mail: a.cockburn@uea.ac.uk 
development course for middle school mathematics teachers. Their use of a range of data collection techniques proved invaluable in identifying tensions, their likely source(s), their evolution and what the authors having tellingly described as, 'the dynamic undercurrents present during professional development.' Thought-provoking material on, for example, the initial mismatch between the teachers' and their professor's expectations of the way in which they might interact is presented. A significant contribution is the development of a theoretical structure to assist future professional development planners in the identification of potential tensions some of which may be avoided, or at least alleviated, by providing, for example, clearer pre-course information.

The final article in this issue is by Dirk Hoek and Koeno Gravemeijer and focuses our attention on teachers of older pupils (i.e. 16-18 year-olds) but, as the others, it invites us to consider some of the complexities and dynamic relationships involved in mathematics education. Using a strategy combining guided intervention and collaborative learning, and following a period of observation, the researchers worked with two teachers over the course of a school year as they endeavoured to change their feedback to pupils from a focus on content to being process-oriented. Extracts from a substantial data set provide some rich material on, for example, how teacher behaviour can have, '... a blocking effect on student contributions because it was the teacher's view that students were expected to accept.' The article illustrates how, although slow, it is possible to alter the ecological environment of the mathematics classroom to good effect through close collaboration and coaching where cycles of 'observations, interpretations, arguments, plans and conjectures can be shared and reconsidered.'

Having gained some insights from courses and classrooms let us turn to conversations. As a researcher and teacher educator, I am sure that my understanding of complex issues has been enriched through discussions with colleagues. Often these can be catalysts for new insights or the seeds for a promising research project. At other times, if we are honest, they are occasions when our own ideas and, dare I suggest, possible prejudices are reinforced and life continues much as normal. In my last editorial (Cockburn 2010), I reflected on the benefits of international collaboration: here I want to focus on more modest—but, potentially, as rich-professional encounters.

Recently I became interested in studying less successful teachers. Such research is fraught with ethical considerations, and therefore, as an initial foray into the area, I decided to talk to primary head teachers about leading and managing their colleagues. This was done in fairly general terms - thus reducing the likelihood of controversial or more sensitive topics arising - but nevertheless the wealth of data gathered revealed far more than I had anticipated. For example, hearing a head teacher likening the range of attitudes across his teaching team to a bell curve gave me a new perspective on teacher change,

...you've got some (teachers) at each end and the majority are in the middle and it's being able to move the majority in the middle in the direction in which you want to go is...is the difficult part...I think one of the keys to it is actually getting the balance in the staff between...shifting the balance, shifting the core dynamic within the staff room away from the negative, you know 'we've done that before' and 'that hasn't worked'... I think it is critical when you start to appoint staff and you move that mass away from the negatives and they become a smaller group... and when you've got more people coming in with new ideas and having different approaches and having a much more open approach to new ideas and challenges... when you shift that balance, that becomes a sort of critical point. And you develop a continuing professional development programme within the school, which they can actually see the point of. (Bob, 23/05/11, brackets added) 
The same series of interviews also gave me a greater appreciation on how head teachers view national subject frameworks. Some considered they provided valuable support for colleagues who were weak in mathematics while others argued that they stifled mathematical creativity and enthusiasm. These views are not necessarily incompatible but, particularly in schools where everyone is encouraged to work in a similar way, such beliefs provide food for thought on the ethos and different types of support, which might be made available in such cases.

A second example of my venturing beyond my usual circle of colleagues has been my work with Carlo Marchini. He is an expert in advanced mathematics while my experience and interests lie very much in the early years' classroom. I think we would both agree that our conversations have not always been easy as they have often been intellectually challenging and required intense concentration. They have, however, been stimulating and offered rich rewards. For example, our joint collaboration has highlighted the need for those teaching the youngest children to have a greater understanding of mathematical concepts than I had previously thought. As a result, Carlo and his colleague, Paola Vighi, were prevailed upon to present complex ideas on number and the key operations in a manner that was accessible to expert early years' teachers with limited mathematical background and often lacking the knowledge and confidence to explore what they did not know (Marchini and Vighi 2008). Similarly our research with other colleagues over the years has acted as a catalyst for us to examine the teaching and learning of equality across the educational spectrum: had we not discussed young children's difficulties with the equals sign it is unlikely that Carlo would have explored the topic with undergraduates or, indeed, embarked on suggestions as to how to teach the concept in the early years' of schooling (see, for example, Parslow-Williams and Cockburn 2008; Marchini et al. 2009; Marchini and Papadopoulos 2011).

My third, and final, example comes from my conversations with colleagues involved in the preparation of person-centred counsellors. Their philosophy is very much to work with the whole person and to follow Carl Rogers' core conditions that include congruence (which, in this context, might be considered as a real and genuine way of working with others); unconditional positive regard (acceptance of, and respect for, those with whom you work) and empathy (understanding of another's thoughts and feelings). In particular this has made me reflect on two areas of direct professional concern: one involves the education of young children and the other surrounds the preparation of prospective elementary mathematics teachers. In both cases I have seen individuals develop and flourish when educated by people who, essentially, adopt a person-centred approach: those lacking in confidence have been transformed into people relishing the prospect of another mathematical challenge! On other occasions I have witnessed children and young adults losing their motivation and, seemingly, their ability to think independently when working under conditions where good results are paramount. I am not for a moment suggesting that educational success is not important but rather I am questioning how best to balance concerns for mathematical achievement with a person-centred approach. Discussing this issue with a colleague at lunch, it became clear that one of his former students has just left teaching because, among other factors, he found it hard to cope with the lack of congruence in some quarters. More specifically, his line manager was always very positive and uncritical in conversation and yet wrote a report to the head teacher clearly expressing concerns about this newly qualified mathematics teacher's performance.

To conclude, there are many complex issues surrounding the teaching, learning and assessing of mathematics. Over the years, our identification, knowledge and understanding have grown. Here I suggest that, by extending our conversations beyond our usual comfort zones, we may develop new insights and further enhance the quality of mathematics education for future generations. 
Acknowledgments The author gratefully acknowledges financial support from the Nuffield Foundation (grant \# EDU/39039) and the British Academy (grant \# LRG-42447).

\section{References}

Cockburn, A. D. (2010). Crossing the divide: Reflecting on the benefits of cross-cultural collaboration. Journal of Mathematics Teacher Education, 13(2), 95-98.

Marchini, C., Cockburn, A. D., Parslow-Williams, P., \& Vighi, P. (2009). Equality relation and structural properties-a vertical study. In F. Arzarello, et al. (Eds.), Proceedings of the sixth conference of European research in mathematics education (pp. 569-578). Paris: Institut National de Recherche Pédagogique.

Marchini, C., \& Papadopoulos, I. (2011). Are useless brackets useful tools for teaching? In B. Ubuz (Ed.), Proceedings of 35th conference of the international group for the psychology of mathematics education (Vol. 3, pp. 185-192). Ankara, Turkey: PME.

Marchini, C., \& Vighi, P. (2008). Everyday numbers under a mathematical magnifying glass. In A. D. Cockburn \& G. Littler (Eds.), Mathematical misconceptions (pp. 123-151). London: Sage.

Parslow-Williams, P., \& Cockburn, A. D. (2008). Equality. In A. D. Cockburn \& G. Littler (Eds.), Mathematical misconceptions (pp. 23-38). London: Sage. 